Supporting Information 


\section{Incorporating Zwitterionic Graphene Oxides into Sodium Alginate Membrane for Efficient Water/Alcohol Separation}

Jing Zhao, ${ }^{\dagger, \ddagger}$ Yiwei Zhu, ${ }^{\dagger},{ }^{\dagger}$ Guangwei He, ${ }^{\dagger, \ddagger}$ Ruisi Xing, ${ }^{\dagger \dagger}$ Fusheng Pan, ${ }^{\dagger,}$ Zhongyi Jiang, *†, Peng Zhang,, ," Xingzhong Cao, ${ }^{\S, / " ~ a n d ~ B a o y i ~ W a n g ~}{ }^{\S, /}$

${ }^{\dagger}$ Key Laboratory for Green Chemical Technology of Ministry of Education, School of Chemical Engineering and Technology, Tianjin University, Tianjin 300072, China

$\$$ Collaborative Innovation Center of Chemical Science and Engineering (Tianjin), Tianjin 300072, China

$\S$ Multi-discipline Research Division, Institute of High Energy Physics, Chinese Academy of Sciences, Beijing 100049, China

" Beijing Engineering Research Center of Radiographic Techniques and Equipment, Beijing 100049, China

* To whom correspondence should be addressed. Fax: +86 222350 0086; Tel: +86 22 2350 0086; E-mail: zhyjiang@tju.edu.cn; 


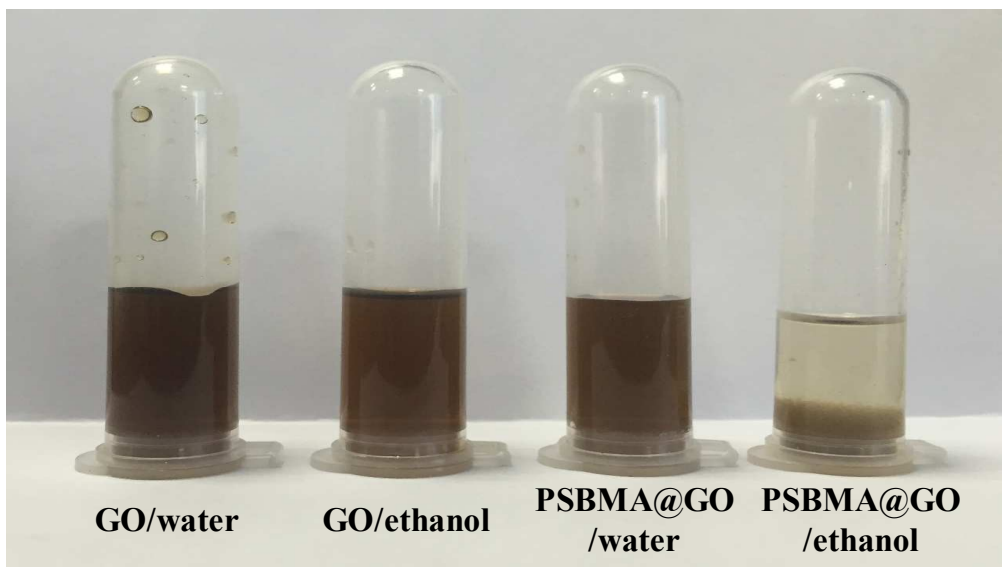

Figure S1. Photographs of GO and PSBMA@GO dispersions with water or ethanol as solvent.

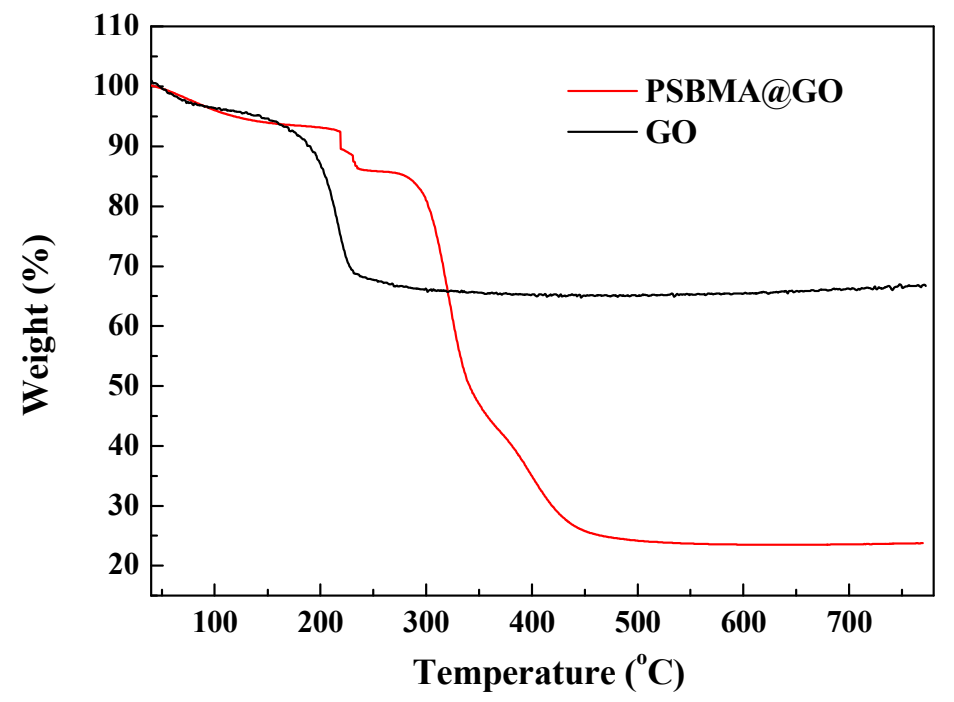

Figure S2. TGA curves of GO and PSBMA@GO.

PSBMA@GO exhibits three weight loss stages: evaporation of water $\left(<150{ }^{\circ} \mathrm{C}\right)$, pyrolysis of the oxygen-containing functional groups on $\mathrm{GO}\left(210{ }^{\circ} \mathrm{C}-240{ }^{\circ} \mathrm{C}\right)$, and the decomposition of grafted PSBMA chains $\left(270{ }^{\circ} \mathrm{C}-500{ }^{\circ} \mathrm{C}\right)$. For $\mathrm{GO}$, the second weight loss occurs in the range of $180{ }^{\circ} \mathrm{C}-230{ }^{\circ} \mathrm{C}$, indicating the improved thermal stability of PSBMA@GO. 


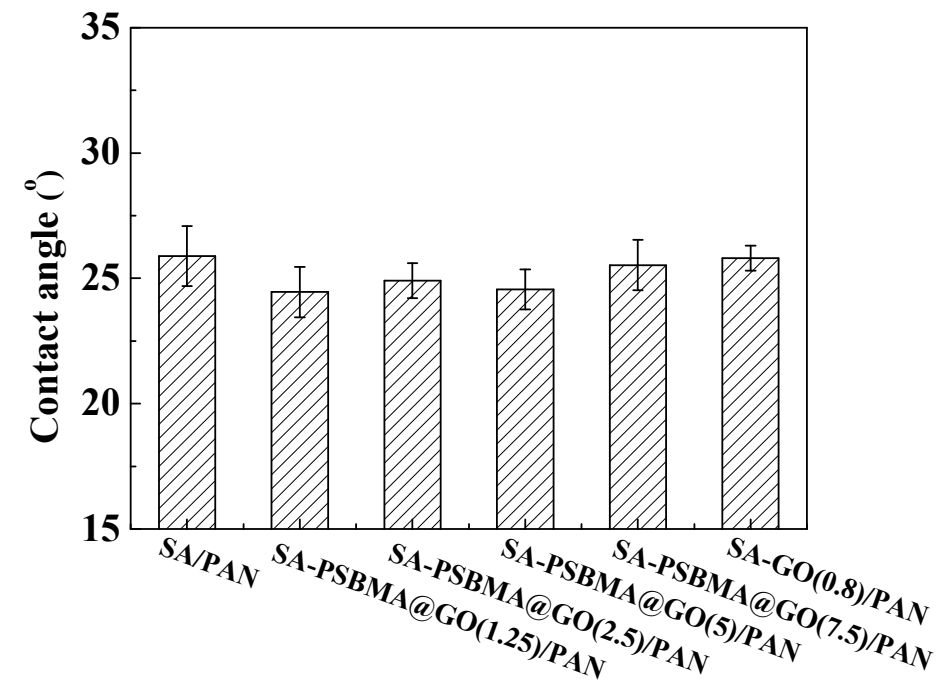

Figure S3. The static water contact angles on nanohybrid membrane surfaces.

The static contact angles of membranes were measured as shown in Figure S3, revealing approximately the same surface hydrophilicity with the mass ratio of PSBMA@GO to SA. The contact angle of SA-GO(0.8)/PAN membrane is also close to that of SA/PAN membrane. The negligible variation of membrane hydrophilicity may arise from the following reasons: (i) the loading contents of PSBMA@GO and GO nanosheets are relatively low; (ii) most of the nanosheets are buried in polymer matrix. Therefore, the surface hydrophilicity of nanohybrid membranes is dominated by SA matrix.

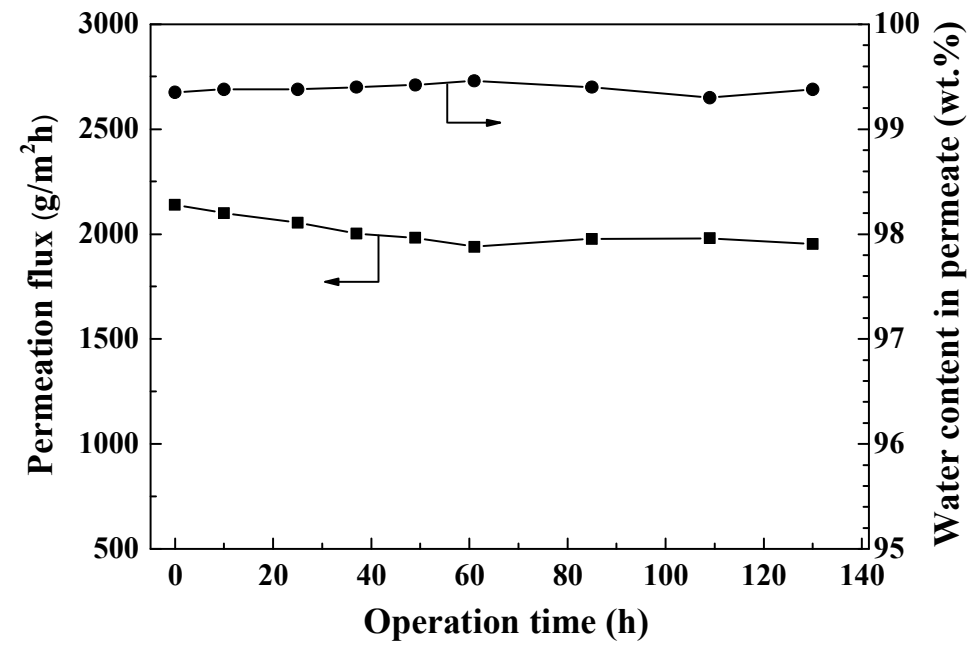

Figure S4. The long-term separation performance of SA-PSBMA@GO(2.5)/PAN membrane. 
Figure S4 shows the long-term separation performance of SA-PSBMA@GO(2.5)/PAN membrane up to $130 \mathrm{~h}$ for $90 \mathrm{wt} \%$ ethanol aqueous solution at $350 \mathrm{~K}$. During the entire test, the permeation flux and water content in permeate fluctuate within a narrow range, implying the desirable structural stability of the nanohybrid membrane. 
Table S1 Comparison of the membrane separation performance in this study with recently reported membranes in literatures.

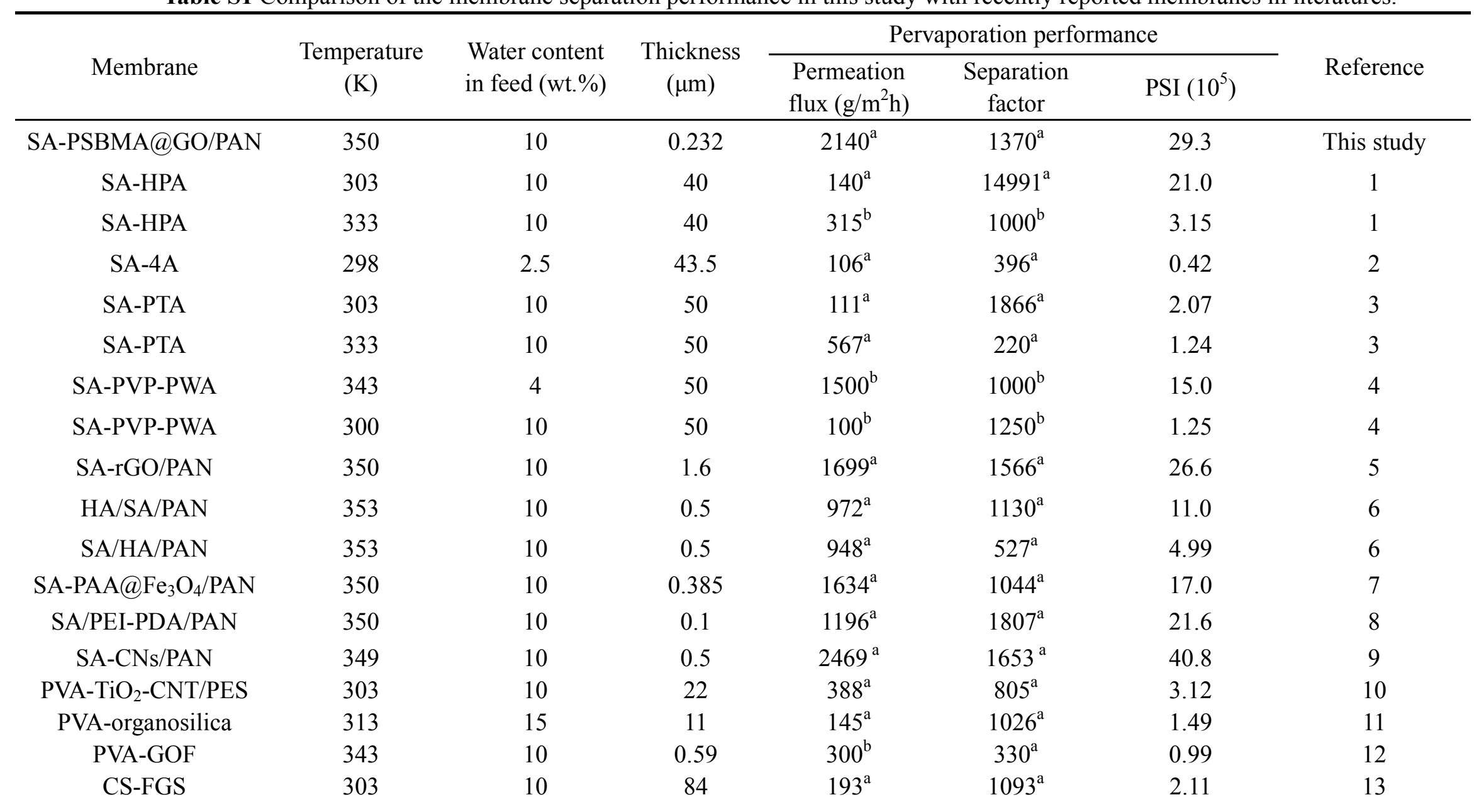




\begin{tabular}{|c|c|c|c|c|c|c|c|}
\hline CS-ZIF7 & 298 & 10 & 21 & $314^{\mathrm{b}}$ & $2885^{\mathrm{b}}$ & 9.06 & 14 \\
\hline Nexar/PEI & 323 & 15 & 0.2 & $1160^{\mathrm{a}}$ & $127^{\mathrm{a}}$ & 1.46 & 15 \\
\hline GE/TA & 350 & 10 & 0.17 & $1336^{\mathrm{a}}$ & $658^{\mathrm{a}}$ & 8.78 & 16 \\
\hline GO/TFNC & 343 & 20 & 0.09 & $2200^{\mathrm{a}}$ & $308^{\mathrm{a}}$ & 6.75 & 17 \\
\hline GO & 297 & 15 & 2 & $250^{\mathrm{a}}$ & $227^{\mathrm{a}}$ & 0.57 & 18 \\
\hline $\mathrm{GO} /$ ceramic & 343 & 10 & 0.26 & $1200^{\mathrm{a}}$ & $250^{\mathrm{a}}$ & 2.99 & 19 \\
\hline
\end{tabular}

${ }^{a}$ Values are obtained directly from the data in references. ${ }^{b}$ Values are estimated from the plots in references. 


\section{References}

(1) Magalad, V. T.; Supale, A. R.; Maradur, S. P.; Gokavi, G. S.; Aminabhavi, T. M. Preyssler Type Heteropolyacid-Incorporated Highly Water-Selective Sodium Alginate-Based Inorganic-Organic Hybrid Membranes for Pervaporation Dehydration of Ethanol. Chem. Eng. J. 2010, 159, 75-83.

(2) Nigiz, F. U.; Dogan, H.; Hilmioglu, N. D. Pervaporation of Ethanol/Water Mixtures Using Clinoptilolite and 4A Filled Sodium Alginate Membranes. Desalination 2012, $300,24-31$

(3) Adoor, S. G.; Rajineekanth, V.; Nadagouda, M. N.; Rao, K. C.; Dionysiou, D. D.; Aminabhavi, T. M. Exploration of Nanocomposite Membranes Composed of Phosphotungstic Acid in Sodium Alginate for Separation of Aqueous-Organic Mixtures by Pervaporation. Sep. Purif. Technol. 2013, 113, 64-74.

(4) Magalad, V. T.; Gokavi, G. S.; Ranganathaiah, C.; Burshe, M. H.; Han, C.; Dionysiou, D. D.; Nadagouda, M. N.; Aminabhavi, T. M. Polymeric Blend Nanocomposite Membranes for Ethanol Dehydration-Effect of Morphology and Membrane-Solvent Interactions. J. Membr. Sci. 2013, 430, 321-329.

(5) Cao, K.; Jiang, Z.; Zhao, J.; Zhao, C.; Gao, C.; Pan, F.; Wang, B.; Cao, X.; Yang, J. Enhanced Water Permeation through Sodium Alginate Membranes by Incorporating Graphene Oxides. J. Membr. Sci. 2014, 469, 272-283.

(6) Gao, C. Y.; Zhang, M. H.; Ding, J. W.; Pan, F. S.; Jiang, Z. Y.; Li, Y. F.; Zhao, J. Pervaporation Dehydration of Ethanol by Hyaluronic Acid/Sodium Alginate Two-Active-Layer Composite Membranes. Carbohydr. Polym. 2014, 99, 158-165.

(7) Zhao, C. H.; Jiang, Z. Y.; Zhao, J.; Cao, K. T.; Zhang, Q.; Pan, F. S. High Pervaporation Dehydration Performance of the Composite Membrane with an Ultrathin Alginate/Poly(acrylic acid)- $\mathrm{Fe}_{3} \mathrm{O}_{4}$ Active Layer. Ind. Eng. Chem. Res. 2014, 53, 1606-1616. 
(8) Zhao, J.; Fang, C.; Zhu, Y.; He, G.; Pan, F.; Jiang, Z.; Zhang, P.; Cao, X.; Wang, B. Manipulating the Interfacial Interactions of Composite Membranes via a Mussel-Inspired Approach for Enhanced Separation Selectivity. J. Mater. Chem. A 2015, 3, 19980-19988.

(9) Cao, K.; Jiang, Z.; Zhang, X.; Zhang, Y.; Zhao, J.; Xing, R.; Yang, S.; Gao, C.; Pan, F. Highly Water-Selective Hybrid Membrane By Incorporating g- $\mathrm{C}_{3} \mathrm{~N}_{4}$ Nanosheets into Polymer Matrix. J. Membr. Sci. 2015, 490, 72-83.

(10) Panahian, S.; Raisi, A.; Aroujalian A. Multilayer Mxed Mtrix Mmbranes Containing Mdified-MWCNTs for Dhydration of Acohol by Prvaporation Pocess. Desalination 2015, $355,45-55$.

(11) Xia, L. L; Li, C. L.; Wang, Y. In-situ Crosslinked PVA/Organosilica Hybrid Membranes for Pervaporation Separations. J. Membr. Sci. 2016, 498, 263-275.

(12) Li, G. H.; Shi, L.; Zeng, G. F.; Li, M.; Zhang, Y. F.; Sun, Y. H. Sharp Molecular-Sieving of Alcohol-Water Mixtures over Phenyldiboronic Acid Pillared Graphene Oxide Framework (GOF) Hybrid Membrane. Chem. Commun. 2015, 51, 7345-7348.

(13) Dharupaneedi, S. P.; Anjanapura, R. V.; Han, J. M.; Aminabhavi, T. M. Functionalized Graphene Sheets Embedded in Chitosan Nanocomposite Membranes for Ethanol and Isopropanol Dehydration via Pervaporation. Ind. Eng. Chem. Res. 2014, 53, 14474-14484.

(14) Kang, C. H.; Lin, Y. F.; Huang, Y. S.; Tung, K. L.; Chung, K. S.; Chen, J. T.; Hung, W. S.; Lee, K. R.; Lai, J. Y. Synthesis of ZIF-7/Chitosan Mixed-Matrix Membranes with Improved Separation Performance of Water/Ethanol Mixtures. J. Membr. Sci. 2013, 438, 105-111.

(15) Shi, G. M.; Zuo, J.; Tang, S. H.; Wei, S.; Chung, T. S. Layer-by-Layer (LbL) Polyelectrolyte Membrane with Nexar ${ }^{\mathrm{TM}}$ Polymer as a Polyanion for Pervaporation Dehydration of Ethanol. Sep. Purif. Technol. 2015, 140, 13-22.

(16) Zhao, J.; Pan, F. S.; Li, P.; Zhao, C. H.; Jiang, Z. Y.; Zhang, P.; Cao, X. Z. Fabrication of Ultrathin Membrane via Layer-by-Layer Self-assembly Driven by Hydrophobic 
Interaction Towards High Separation Performance. ACS Appl. Mater. Interfaces 2013, 5, $13275-13283$.

(17) Yeh, T. M.; Wang, Z.; Mahajan, D.; Hsiao, B. S.; Chu, B. High Flux Ethanol Dehydration Using Nanofibrous Membranes Containing Graphene Oxide Barrier Layers. J. Mater. Chem. A 2013, 1, 12998-13003.

(18) Tang, Y. P.; Paul, D. R.; Chung, T. S. Free-Standing Graphene Oxide Thin Films Assembled by a Pressurized Ultrafiltration Method for Dehydration of Ethanol. $J$. Membr. Sci. 2014, 458, 199-208.

(19) Li, G. H.; Shi, L.; Zeng, G. F.; Zhang, Y. F.; Sun, Y. H. Efficient Dehydration of the Organic Solvent through Graphene Oxide (GO)/Ceramic Composite Membranes. RSC Adv. 2014, 4, 52012-52015. 